\title{
Advanced maternal age: ethical and medical considerations for assisted reproductive technology
}

This article was published in the following Dove Press journal:

International Journal of Women's Health

16 August 2017

Number of times this article has been viewed

\author{
Brittany J Harrison' \\ Tara N Hilton' \\ Raphaël N Rivière' \\ Zachary M Ferraro ${ }^{1-3}$ \\ Raywat Deonandan ${ }^{4}$ \\ Mark C Walker ${ }^{1-3,5}$ \\ 'Faculty of Medicine, University \\ of Ottawa, Ottawa, ON, Canada; \\ ${ }^{2}$ Division of Maternal-Fetal \\ Medicine, University of Ottawa, \\ The Ottawa Hospital, Ottawa, ON, \\ Canada; ${ }^{3}$ Ottawa Hospital Research \\ Institute, The Ottawa Hospital, \\ Ottawa, ON, Canada; ${ }^{4}$ University \\ of Ottawa Interdisciplinary School \\ of Health Sciences, Ottawa, ON, \\ Canada; ${ }^{5}$ Department of Obstetrics, \\ Gynecology and Newborn Care, The \\ Ottawa Hospital, Ottawa, ON, Canada
}

Correspondence: Brittany J Harrison McMaster University, Faculty of Medicine, 100 Main St West, Hamilton, ON L8P IH6, Canada

Tel +l 9052205617

Email harrisonbrittj@gmail.com
Objectives: This review explores the ethical and medical challenges faced by women of advanced maternal age who decide to have children. Assisted reproductive technologies (ARTs) make post-menopausal pregnancy physiologically plausible, however, one must consider the associated physical, psychological, and sociological factors involved.

Methods: A quasi-systematic review was conducted in PubMed and Ovid using the key terms post-menopause, pregnancy + MeSH terms [donations, hormone replacement therapy, assisted reproductive technologies, embryo donation, donor artificial insemination, cryopreservation]. Overall, 28 papers encompassing two major themes (ethical and medical) were included in the review.

Conclusion: There are significant ethical considerations and medical (maternal and fetal) complications related to pregnancy in peri- and post-menopausal women. When examining the ethical and sociological perspective, the literature portrays an overall positive attitude toward pregnancy in advanced maternal age. With respect to the medical complications, the general consensus in the evaluated studies suggests that there is greater risk of complication for spontaneous pregnancy when the mother is older (eg, $>35$ years old). This risk can be mitigated by careful medical screening of the mother and the use of ARTs in healthy women. In these instances, a woman of advanced maternal age who is otherwise healthy can carry a pregnancy with a similar risk profile to that of her younger counterparts when using donated oocytes.

Keywords: maternal age, medical, ethical, assisted reproduction, menopause

\section{Introduction}

Recent advances in assisted reproductive technologies (ARTs) have made it more possible for older couples to conceive. With the advent of ARTs, it is now physiologically possible for post-menopausal women (PMW) to become pregnant; as well, ARTs are being used with increased frequency for women of advanced maternal age (AMA). ${ }^{1}$ In parallel with technological advances, a cultural shift has seen greater societal acceptance of women having children later in life. Consequently, a post-menopausal state is no longer a barrier to gestation in areas of the world where this social viewpoint is shared, and where ARTs are available.

However, AMA and pregnancy after physiologic menopause, can give rise both to a number of medical complications and to a series of ethical challenges. ${ }^{1,2}$ This review aims to critically appraise and evaluate the existing literature surrounding this phenomenon, and give recommendations concerning pregnancy complication risks, as well as to discuss some of the practical aspects of post-menopausal pregnancy (PMP). 


\section{Methods}

\section{Search strategy}

PubMed and Ovid were searched to identify relevant literature pertaining to PMP and the associated ethical and medical challenges. To complement the comprehensive Ovid search, a PubMed search was conducted using the search terms "post-menopausal AND pregnancy + MeSH Terms [donations, hormone replacement therapy, assisted reproductive technologies, embryo donation, donor artificial insemination, cryopreservation]" with no filters applied. This broad search, which was completed in November 2016, ensured we captured all relevant literature and yielded 144 papers in total. These titles and abstracts were then screened and included if they met the following inclusion criteria: written in the English language and contained any discussion of the ethical and medical (maternal and fetal) complications of pregnancy in AMA. For our purposes, AMA is defined as $>35$ years. There were no exclusions based on type of article.

All abstracts were reviewed for content relevance and 110 papers were excluded as they were out of scope and had an alternate focus such as hormone replacement, neoplasms caused by exogenous estrogen, and disorders not associated with pregnancy. The remaining 34 papers were read in detail by two reviewers and eliminated if they did not pertain to either the ethical or medical challenges that accompany a PMP; this left 28 papers for review. This is demonstrated in the flow chart of Figure 1.

\section{Synthesis strategy}

The remaining 28 papers were first divided into two broad categories for review: those pertaining to primarily ethical discussions and those encompassing medical complications. Key details pertaining to our objectives and inclusion criteria were extracted and tabulated (Tables 1 and 2).

For the ethical section, review of 12 papers was done equally by two reviewers. Key arguments were extracted out of the text, combined into themes, and summarized according to argument in Table 1.

For the medical complications section, 16 papers were reviewed equally by two separate reviewers. Descriptive information including patient characteristics, sample size, study design, and the fetal and maternal medical complications associated with AMA were extracted from the papers, and summarized in Table 2. These reviewers split the papers and screened for qualitative and quantitative content in full.

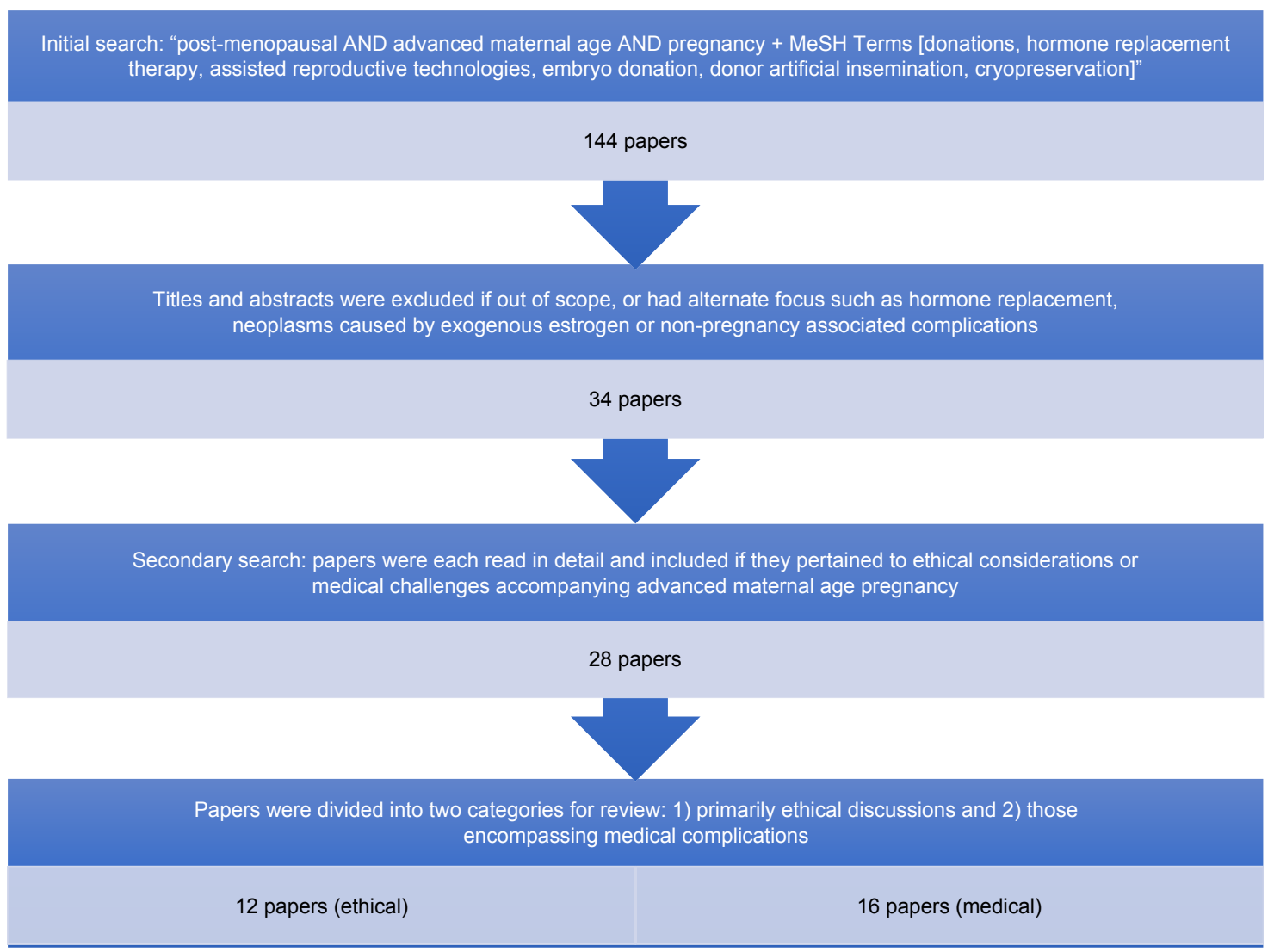

Figure I Flow chart demonstrating selection of papers. 
Table I Ethical arguments: post-menopausal pregnancy

\begin{tabular}{|c|c|c|}
\hline Author, year & Overarching theme & Conclusion \\
\hline Benshushan and & Post-menopausal women (PMW) possess many qualities which enhance their parenting abilities. & For \\
\hline Schenker,' 1993 & Time and experience is needed to fully understand the effect on children. & \\
\hline Edwards, ${ }^{14} 1993$ & Patient autonomy must not be violated. & For \\
\hline Paulson and & Individualized care and decision-making is required. & For \\
\hline Sauer, ${ }^{17} 1995$ & Broad categorical exclusions are not fitting for in vitro fertilization (IVF) in PMW. & \\
\hline \multirow[t]{2}{*}{ Mori, ${ }^{23} 1995$} & Patient autonomy must not be violated. & For \\
\hline & $\begin{array}{l}\text { However, to protect child welfare, the procedure should be limited to women below } 60 \text { years of age } \\
\text { at present. }\end{array}$ & \\
\hline \multirow[t]{2}{*}{ Parks, ${ }^{6} 1996$} & Equality must not be violated. & For \\
\hline & Ageism and sexism underlie most arguments against IVF in PMW. & \\
\hline Eisenberg and & Patient autonomy must not be violated. & For \\
\hline Schenker, ${ }^{8} 1997$ & $\begin{array}{l}\text { However, to protect child welfare, the procedure should be limited to women below } 55 \text { years of age } \\
\text { at present. }\end{array}$ & \\
\hline American Reproductive & Infertility is natural among PMW and nature should not be violated. & Against \\
\hline \multicolumn{3}{|l|}{ Medicine, ${ }^{24} 2004$} \\
\hline Landau, ${ }^{7} 2005$ & $\begin{array}{l}\text { The risks and costs outweigh the benefits and success associated with IVF in PMW. } \\
\text { IVF in PMW has the potential to increase human suffering. }\end{array}$ & Against \\
\hline Cutas, ${ }^{9} 2007$ & $\begin{array}{l}\text { Patient autonomy must not be violated. } \\
\text { It cannot successfully be shown that IVF in PMW is against interests of children. } \\
\text { A woman's age, marital status, and motivation for pregnancy are not sufficient reasons to deny her IVF. }\end{array}$ & For \\
\hline Smajdor, 2008 & $\begin{array}{l}\text { Most arguments against IVF in PMW are based on unfounded assumptions such as choices earlier in life. } \\
\text { Age alone is not adequate to deprioritize PMW as donated oocyte recipients. } \\
\text { The ethics of oocyte donation and IVF as procedures need to be assessed independent of age. }\end{array}$ & For \\
\hline $\begin{array}{l}\text { Shufaro and } \\
\text { Schenker, }{ }^{10} 2012\end{array}$ & $\begin{array}{l}\text { Age limit, transparent guidelines, and rigorous screening procedures are needed, but there are no ethical } \\
\text { grounds to prohibit IVF in PMW. }\end{array}$ & For \\
\hline \multirow[t]{2}{*}{ Ekberg," 2014} & Patient autonomy must not be violated. & For \\
\hline & There are no ethical grounds to prohibit IVF in PMW. & \\
\hline
\end{tabular}

Table 2 Medical complications of advanced maternal age

\begin{tabular}{|c|c|c|c|c|c|}
\hline $\begin{array}{l}\text { Author, } \\
\text { year }\end{array}$ & Methods & $\begin{array}{l}\text { Number of } \\
\text { subjects }\end{array}$ & $\begin{array}{l}\text { Number } \\
\text { of clinical } \\
\text { pregnancies }\end{array}$ & $\begin{array}{l}\text { Maternal } \\
\text { characteristics }\end{array}$ & Conclusions \\
\hline \multicolumn{6}{|c|}{ Donor oocyte studies } \\
\hline $\begin{array}{l}\text { Sauer et al, }{ }^{25} \\
1992\end{array}$ & $\begin{array}{l}\text { Prospective study of } \\
100 \text { patients using oocyte } \\
\text { donation for infertility. }\end{array}$ & 100 & 34 & $\begin{array}{l}\text { Women } 40+\text { requesting } \\
\text { oocyte donation. }\end{array}$ & $\begin{array}{l}\text { Success rates are similar to younger } \\
\text { counterparts with assisted reproductive } \\
\text { technologies (ARTs). }\end{array}$ \\
\hline $\begin{array}{l}\text { Antinori } \\
\text { et al, }{ }^{26} 1993\end{array}$ & $\begin{array}{l}\text { Oocyte donation by in vitro } \\
\text { fertilization (IVF) and embryo } \\
\text { transfer in } 82 \text { women. }\end{array}$ & 82 & 32 & $\begin{array}{l}\text { Average age } 48 \\
\text { (26-60 range). } \\
\text { 7I were over } 40 . \\
\text { Normal prenatal serology.* }\end{array}$ & $\begin{array}{l}\text { Uterus of a post-menopausal woman has } \\
\text { the great ability to maintain a pregnancy. }\end{array}$ \\
\hline $\begin{array}{l}\text { Sauer et al, }{ }^{19} \\
1993\end{array}$ & $\begin{array}{l}\text { Oocyte donation by embryo } \\
\text { transfer. } \\
\text { All gametes anonymously } \\
\text { donated. }\end{array}$ & 14 & 9 & $\begin{array}{l}50+\text { (range } 50-59) \\
\text { Normal prenatal serology.* }\end{array}$ & $\begin{array}{l}\text { Women beyond natural menopause may } \\
\text { still achieve uterine receptivity. Uterus } \\
\text { able to maintain a pregnancy with correct } \\
\text { hormonal support. }\end{array}$ \\
\hline $\begin{array}{l}\text { Antinori } \\
\text { et al, }{ }^{22} 1995\end{array}$ & Oocyte donation program. & 162 & 44 & $\begin{array}{l}\text { I I } 3 / 162 \text { were }>45 \text { years } \\
\text { old. } \\
49 \text { were }<45 \text { years old. } \\
75 \% \text { reached term. }\end{array}$ & $\begin{array}{l}\text { Women in menopause, if selected } \\
\text { carefully, are able to bring pregnancy } \\
\text { to term with the same success as their } \\
\text { younger counterparts. }\end{array}$ \\
\hline $\begin{array}{l}\text { Sauer et al, }{ }^{27} \\
1995\end{array}$ & Oocyte donation case study. & I & 3 & $\begin{array}{l}\text { G3P3. } \\
\text { Menopause diagnosis } \\
\text { at age } 50 \text { taking HRT. } \\
\text { No hypertension. } \\
\text { No diabetes mellitus. }\end{array}$ & $\begin{array}{l}\text { The overall health of the mother } \\
\text { remained stable throughout the } \\
\text { pregnancy. } \\
\text { Her chronological age did not appear to } \\
\text { alter the pregnancy course or outcome. }\end{array}$ \\
\hline $\begin{array}{l}\text { Antinori } \\
\text { et al, }{ }^{28} 2002\end{array}$ & $\begin{array}{l}\text { Post-menopausal oocyte } \\
\text { donation programs. Total of } \\
\text { I,I50 accepted into program. }\end{array}$ & $\mathrm{I}, 150$ & 489 & Women aged $45-63$ years. & $\begin{array}{l}\text { Post-menopausal women do not have a } \\
\text { greater risk associated with pregnancy if } \\
\text { they do not exhibit any medical disorders. }\end{array}$ \\
\hline
\end{tabular}


Table 2 (Continued)

\begin{tabular}{|c|c|c|c|c|c|}
\hline $\begin{array}{l}\text { Author, } \\
\text { year }\end{array}$ & Methods & $\begin{array}{l}\text { Number of } \\
\text { subjects }\end{array}$ & $\begin{array}{l}\text { Number } \\
\text { of clinical } \\
\text { pregnancies }\end{array}$ & $\begin{array}{l}\text { Maternal } \\
\text { characteristics }\end{array}$ & Conclusions \\
\hline $\begin{array}{l}\text { Paulson et al, } \\
2002\end{array}$ & $\begin{array}{l}\text { Oocyte donation in women } \\
\text { over } 50 .\end{array}$ & 121 & 55 & $\begin{array}{l}77 \text { post-menopausal } \\
\text { women (50-63). } \\
\text { Normal prenatal serology** }\end{array}$ & $\begin{array}{l}\text { Appropriately screened women aged } 50 \\
\text { and older can successfully conceive via } \\
\text { oocyte donation and experience similar } \\
\text { pregnancy rates, multiple gestations, and } \\
\text { spontaneous abortion rates as younger } \\
\text { recipients. }\end{array}$ \\
\hline $\begin{array}{l}\text { Fonttis et al, }{ }^{29} \\
2004\end{array}$ & $\begin{array}{l}\text { Case report. } \\
\text { Post-menopausal woman } \\
\text { with cancer undergoing IVF. }\end{array}$ & I & 0 & $\begin{array}{l}\text { Did not receive her first } \\
\text { progesterone injection at } \\
\text { the correct time. }\end{array}$ & $\begin{array}{l}\text { One gestational sac was recorded at } \\
8 \text { weeks of gestation by ultrasonography } \\
\text { and a healthy baby was born. }\end{array}$ \\
\hline $\begin{array}{l}\text { Krieg et al, }{ }^{21} \\
2008\end{array}$ & $\begin{array}{l}\text { IFV oocyte recipients vs } \\
\text { autologous IFV reception. }\end{array}$ & 179 & 450 & $\begin{array}{l}\text { Women over } 38 \text { years of } \\
\text { age vs all infertile women } \\
\text { with donor oocyte. }\end{array}$ & $\begin{array}{l}\text { Women undergoing IVF with donor } \\
\text { oocytes are not at increased risk for } \\
\text { complications of neonate or pregnancy } \\
\text { compared with women of advanced } \\
\text { maternal age. }\end{array}$ \\
\hline $\begin{array}{l}\text { Usta and } \\
\text { Nassar, } \\
2008\end{array}$ & $\mathrm{~N} / \mathrm{A}$ & $\mathrm{N} / \mathrm{A}$ & N/A & $\mathrm{N} / \mathrm{A}$ & $\begin{array}{l}\text { Although these patients seem to be at } \\
\text { higher risks of maternal and perinatal } \\
\text { morbidity and mortality, pregnancies in } \\
\text { such women are still considered relatively } \\
\text { safe in the absence of preexisting medical } \\
\text { conditions. }\end{array}$ \\
\hline $\begin{array}{l}\text { Ameratunga } \\
\text { et al, }{ }^{20} \\
2009\end{array}$ & $\begin{array}{l}\text { Retrospective analysis of } \\
54 \text { recipients with either } \\
\text { premature ovarian failure } \\
\text { or physiological menopause } \\
\text { undergoing oocyte donation. }\end{array}$ & 54 & 40 & $\begin{array}{l}\text { Group A (POF group) } \\
\text { with an average age of } \\
28.3 \text { years }( \pm 6.1) \text { vs post- } \\
\text { menopausal group. }\end{array}$ & $\begin{array}{l}\text { Oocyte donation in both premature } \\
\text { ovarian failure and physiological } \\
\text { menopause is successful. } \\
\text { Higher rates of complications occur in } \\
\text { older women. } \\
\text { Individual risk-factor analysis needs to } \\
\text { be considered when counseling post- } \\
\text { menopausal women. }\end{array}$ \\
\hline $\begin{array}{l}\text { Karadag and } \\
\text { Roffi, }{ }^{31} \\
2009\end{array}$ & $\begin{array}{l}\text { Case report. 52-year-old } \\
\text { woman with IVF pregnancy. }\end{array}$ & I & 2 & $\begin{array}{l}\text { There was nothing unusual } \\
\text { in her medical history, } \\
\text { and no cardiovascular risk } \\
\text { factors were identified. }\end{array}$ & $\begin{array}{l}\text { Uneventful delivery by cesarean section. } \\
\text { Further studies are required to determine } \\
\text { the degree of risk that these pregnancies } \\
\text { confer in regard to the potentially } \\
\text { catastrophic complication of spontaneous } \\
\text { coronary artery dissection. }\end{array}$ \\
\hline \multicolumn{6}{|c|}{ Non-donor oocyte studies } \\
\hline $\begin{array}{l}\text { Benshushan } \\
\text { and Schenker,' } \\
1993\end{array}$ & Review & $\mathrm{N} / \mathrm{A}$ & N/A & N/A & $\begin{array}{l}\text { To minimize maternal health risks, } \\
\text { thorough evaluation of maternal health } \\
\text { should be evaluated before pregnancy. }\end{array}$ \\
\hline $\begin{array}{l}\text { Hirst and } \\
\text { Ferrier, }{ }^{32} \\
2004\end{array}$ & $\begin{array}{l}\text { Case study: post-menopausal } \\
\text { woman on HRT becomes } \\
\text { pregnant with hydatidiform } \\
\text { mole. }\end{array}$ & 1 & 0 & $\begin{array}{l}55 \text {-year-old nulliparous } \\
\text { woman. }\end{array}$ & $\begin{array}{l}\text { Hydatidiform mole pregnancy. } \\
\text { Women in this age group are often } \\
\text { thought to be post-menopausal. It is } \\
\text { important to remain suspicious of molar } \\
\text { disease in this age group. }\end{array}$ \\
\hline Tower, ${ }^{4} 2009$ & Review & $\mathrm{N} / \mathrm{A}$ & N/A & $\mathrm{N} / \mathrm{A}$ & $\begin{array}{l}\text { Pregnancy in post-menopausal women is } \\
\text { associated with increased risks. Women } \\
\text { conceiving spontaneously are at significant } \\
\text { risk of fetal aneuploidy, thus they must be } \\
\text { offered screening. }\end{array}$ \\
\hline $\begin{array}{l}\text { Schimmel } \\
\text { et al, }{ }^{3} 2015\end{array}$ & $\begin{array}{l}\text { Retrospective, single } \\
\text { center study comparing } \\
\text { spontaneously conceived in } \\
\text { age } 24-27 \text { vs }>35 \text {. }\end{array}$ & $\begin{array}{l}24,579 \\
\text { eligible } \\
\text { women }\end{array}$ & 80,053 & $\begin{array}{l}\text { ART excluded. } \\
\text { Single pregnancies. } \\
\text { Normal prenatal serology.* }\end{array}$ & $\begin{array}{l}\text { Advanced maternal age has more adverse } \\
\text { maternal and neonatal outcomes than } \\
\text { younger women; large for gestational age, } \\
\text { cesarean section. } \\
\text { Primiparous women are at higher risk } \\
\text { than multiparous. }\end{array}$ \\
\hline
\end{tabular}

Note: *Normal prenatal testing: medical screening of stress test, mammography, chest X-ray, glucose tolerance test, partial prothrombin time/international normalized ratio, thyroid-stimulating hormone, complete blood count, cervical pap, HIV, syphilis, hepatitis screening.

Abbreviations: HRT, hormone replacement therapy; N/A, not available; POF, premature ovarian failure. 
A third reviewer reviewed all papers, and was the source of consensus.

\section{Results}

Our search yielded 12 qualitative articles related to the ethics of in vitro fertilization (IVF) in PMW. A summary of results and themes that emerged for the various arguments, both for and against, is presented in Table 1. The conclusion of 16 case-control, retrospective studies, narrative review papers, and clinical reports reveal that maternal, fetal, and neonatal complications are greater in PMW and pregnancies of AMA. ${ }^{11,12,15,16}$ The reviewed studies were heterogeneous in nature which makes direct comparisons difficult due to lack of homogeneity. Nonetheless, the overarching conclusions were similar and presented in Table 2.

\section{Ethical considerations of AMA IVF as an ethical procedure}

Underlying all discussions of IVF in PMW is the question of whether IVF itself is an ethical procedure to undertake in women of AMA. ${ }^{1}$ Challenges include the ethics surrounding the loss of fertilized eggs during the IVF procedure, as well as whether humans should technically augment a natural process. Although worthy of discussion, these arguments are beyond the scope of this review, as they apply in large part to pre-menopausal women.

There are economic and technical concerns about IVF for PMW that have been frequently addressed in the literature. For example, IVF in any population is both costly and considered to have a low success rate, ${ }^{2}$ which may be lower in the subgroup of PMW. It is further argued that it is unjust to give women false hope that IVF can facilitate conception. This belief may, intentionally or not, foster the notion that delaying pregnancy in women of AMA is a feasible option, knowing that IVF will be available and likely successful when they are ready. ${ }^{3}$ Thus, it is advisable that women be fully informed about the success rates and risks associated with ARTs, especially if such knowledge affects their longterm personal planning.

Some critics argue that it is unacceptable to offer ART to PMW for whom bearing children is "unnatural". ${ }^{4-7}$ Ekberg ${ }^{11}$ argues that IVF in PMW medicalizes the natural process of menopause. However, this line of reasoning falters when one considers that all modern medical procedures effectively defy nature, or at least the "natural" progress of disease. 5,7

The argument is essentially that IVF in PMW is unethical as it is not correcting a disease or a malfunctioning organ system. De Wert ${ }^{12}$ argues that IVF in PMW simply reverses part of the natural process of aging. ${ }^{3}$ Kluge $^{13}$ accepts infertility as an illness for people who are of reproductive age (ie, not PMW). ${ }^{3}$ Within this framework, Kluge compares PMW to prepubescent girls and suggests that infertility in these groups is not a disease requiring treatment, but rather the natural life course of female biology. Landau criticizes Kluge's arguments, stating that to compare PMW to prepubescent girls ignores and denigrates the maturity and experience of PMW. Overall, Landau contests that there is no ethical, medical or economic basis for denying IVF to PMW unless expensive and minimally successful procedures are denied to women of all ages.

\section{Autonomy}

It is important to acknowledge the importance of autonomy in debates concerning health care ethics.

When trying to determine the age at which PMP should be offered, one must consider who will decide: physicians, government, or some kind of committee? For Edwards ${ }^{14}$ physicians have no independent moral authority over the patient to judge the acceptability of PMP. This implies that physicians may object only on the basis of direct harm to the patient. Ekberg ${ }^{7}$ advocates for ARTs on the basis of reproductive autonomy. Others prioritize maternal and fetal health over any sort of autonomy. ${ }^{4}$ This debate reflects a larger bioethical question which arises in policy circles: to what extent must a medical procedure reflect community values, and therefore migrate from individual choice to enter the jurisdiction of state bodies?

Paulson and Sauer ${ }^{17}$ argues for somewhat unrestricted access to ART by invoking Western ideals of a free society where individual rights and privacy are prioritized. However, the value of patient autonomy is not an absolute. If society denies access to a specified group of patients, it sets a precedent for excluding other groups from being offered certain procedures. ${ }^{11}$ The reproductive rights of younger women who have a decreased life expectancy due to other medical conditions are not limited by our society. For example, women with systemic lupus erythematosus, type 1 diabetes or chronic renal failure are not restricted from reproducing. This indicates society's general respect for the rights of any individual's choice to procreate. ${ }^{11}$

Edwards ${ }^{10}$ discourages moral posturing from physicians, but strongly cautions against involvement of politicians given historical evidence of the abuses created by governmentsponsored programs. Physicians should shoulder the responsibility of assessing maternal and fetal health, while ethicists may provide further guidance on its feasibility and the age at which it should be applied, given the patient's sociocultural circumstances. 
Patient autonomy not only raises ethical flags with regards to decisions of who is eligible for ART and how the process would be regulated, it also raises the challenge of weighing the autonomy of the PMW against the well-being of the resulting child. Braverman offers a succinct discussion of the possible effects of encouraging parenthood among elderly men and women. ${ }^{15}$ These include causing anxiety in the child over the impending loss of a parent and the burden of becoming a caregiver for a parent at a young age. There is preliminary evidence for such adverse outcomes in, eg, a Swedish study of 862,554 children which found that parental loss from natural deaths was associated with a small increased risk for mental health consequences in adulthood. ${ }^{16}$ They also found that losing a parent at a young age was associated with higher risk for hospitalization and outpatient mental health care. Thus, while ART for PMW does seem to promote autonomy of women in most contexts, we must critically assess whether it concurrently infringes on the autonomy and well-being of the resultant child. Conversely, we must also mention the advantages that are at play with older parents; they are likely extremely committed to parenthood, probably wiser, and are aware of the pitfalls of parenthood as they have been observing it in society. In addition, they have had time to make their decision to parent, and are more likely to be financially secure. ${ }^{10}$

\section{Resource allocation}

The issue of resource allocation is a point of discord in the discussion of IVF. The procedure relies upon the gametes, which are often donated. Critics of IVF for PMW argue there should to be a way of prioritizing oocyte recipients. ${ }^{6}$ It has been stated that PMW should not be allowed to receive oocytes if they are childless due to their own free choices earlier in life (such as delaying pregnancy until they have established their career). ${ }^{1}$ Others argue that oocytes are a scarce resource and therefore recipients must be prioritized according to clinical need. In other words, there must be criteria to prioritize women seeking IVF. For example, menopause is a natural result of aging, infertility is not. Therefore, being young/infertile constitutes a greater clinical need than being post-menopausal/infertile. ${ }^{1,6}$ Eisenberg and Schenker ${ }^{8}$ point out that oocytes tend to be allocated to women who are able to pay rather than to women who are in greatest need. They argue that priority should be given to women who have been deprived of children due to infertility in their child-bearing years.

On the topic of clinical need, while some argue that young infertile women have a greater clinical need for treatment than PMW, it can be counter-argued that neither group has a true clinical need, since in both groups, treatment does not cure disease or prolong life. ${ }^{1}$ Given that PMW can successfully carry and give birth to a child, they have as much to gain from treatment as younger women. ${ }^{1}$ Denying IVF to PMW who have had their children pass away, want children from a new marriage, or were infertile during the pre-menopausal period, is unfair. ${ }^{6}$ On the topic of "clinical need", when prioritizing a finite resource (donated oocytes) for a high-cost/low-success procedure, each case should be assessed individually on its merits. ${ }^{2}$

Smajdor ${ }^{5}$ presented numerous counter-arguments to unrestricted freedom of choice. For example, it is assumed that a PMW has had ample opportunity to conceive naturally but have chosen not to; this statement feeds into the attitude that women have a duty to reproduce at the "appropriate time" and can be socially condemned if they do not. ${ }^{1}$ It may be assumed that career ambitions and a desire for social/economic status are at the root of women's "failure" to make appropriate reproductive choices. ${ }^{1}$ However, many women who have not reproduced before menopause made no conscious decision about procreation at all. ${ }^{1}$ The freedom to choose to bear a child is often dependent on numerous factors such as relationship, social, and economic status. Women who choose to have children when they lack stability in these areas are subject to much criticism. ${ }^{1}$ Smajdor goes on to question: if a woman did freely make the choice not to have a child despite being fully able and in the right circumstances at a younger age, would it then be right to withhold IVF treatment from her? Compare this to an alternative disease state that could be caused by lifestyle choices such as type 2 diabetes. It is not acceptable to withhold treatment on a punitive basis in these cases, so why should it be acceptable for PMW seeking IVF? Thus, Smajdor argues, a woman's choices early in life should not be used as a reason to limit her choices later in life.

\section{Cultural considerations}

The ethics of disallowing PMP in order to maintain cultural traditions is complicated. ART threatens the traditional concept of family and mothers of natural reproductive age, but many other parenting structures also do this. ${ }^{7}$ And while other areas of parenting structure deviate from cultural tradition, it does not make it ethically sound or right, it does suggest that freedoms are granted to other parenting groups and structures and these "freedoms" should be explored in the context of PMP and ART. Thus, it is difficult to reject ART purely on the basis of cultural tradition, unless one 
has a threshold on the gradient of what a "normal" family structure ought to resemble.

Does PMP truly enable women to have greater control over the age at which she becomes pregnant? This question is one of autonomy, but also has deep cultural implications. It may seem that IVF can only increase reproductive autonomy by prolonging fertility. The reality is that PMP is not always successful, yet has great physical, psychological, and financial costs. Many women will remain infertile; thus, in this respect, full control is illusory. ${ }^{3}$

It is useful to acknowledge the role of extended family on a child's health and upbringing. Many cultures highly value grandparents; in some countries, like Romania and China, the child's care can be almost entirely entrusted to them.,12 Other studies that have examined grandparents as primary caregivers demonstrate that there is no obvious disadvantage concerning health or well-being of the child. ${ }^{11,17}$ These findings support the notion that children raised by older parents have an equal opportunity for normal development trajectory. Others, such as Smith et al, ${ }^{18}$ argue that although children raised by older parents suffer no obvious disadvantage, this alone does not position these new technologies as ethically justifiable.

An interesting counter-argument to PMP is that prolongation of fertility via IVF could cause stress and pressure for childless women to become pregnant. In Israel eg, there are immense social pressures for women to bear children and electing to remain childless is a social stigma. ${ }^{7}$ In a system where PMP is accepted and the dominant culture discriminates against childlessness, women may be forced to consider PMP even when they do not want it. Here, the prolongation of fertility may in fact repress female autonomy. Thus, between and within various cultures emerge unique and challenging factors that are crucial components of decisionmaking for PMP.

\section{Religious and legal considerations}

There are religious objections to IVF and oocyte donation, but these are not specific to PMW. Briefly, IVF is not advisable under some strict interpretations of Roman Catholic, Eastern Orthodox, or Protestant Christian doctrine. ${ }^{4}$ Some religious scholars also argue that IVF using donated gametes should be discouraged among Islamic or in Jewish communities if the donor is a married woman. ${ }^{4}$ What is permissible under religious law is further complicated by the possibility of using a surrogate gestating mother. Buddhism and Hinduism appear to have no restrictions on the use of ARTs. ${ }^{4}$
In addition to religious concerns, there are several legal ramifications to consider concerning PMP. Reproductive tourism is something that is already an issue for IVF technology, ${ }^{7}$ and seems to be an easy fit for those seeking PMP, especially if it involves the seeking of affordable surrogate gestating mothers. Legislation to prevent the exploitation of oocyte donors is something that many jurisdictions may wish to consider. Policies around the extent of anonymity of gamete donors is protected, or the degree to which compensation for donation or brokerage of donors is permitted or encouraged will need to be developed and debated.

While PMP specifically, and ART in general, will affect a relatively small proportion of the population, it necessarily involves questions of life, death, identity and definitions of family. Therefore, how a society conceptualizes its responses to the ethical challenges posed by these technologies will reflect the essential values of that society. Viewed through this lens, issues related to PMP and ART are of pressing importance.

Ethical arguments can be presented both in favor of and against PMP, although current literature generally supports the notion of PMP as ethically just. Among the primary arguments against PMP as unethical is that it has the potential to increase suffering by presenting PMP as a foolproof option, when in reality it is a high-cost and low-success procedure, often complicated by religious and cultural objections. ${ }^{7}$ Many also consider PMP to be an unnecessary medicalization of a natural life process, ${ }^{14}$ given that menopause-driven infertility is not a disease. In contrast, supporters of PMP argue that individual choice and autonomy should be prioritized as the main determinant for justifying PMP. Furthermore, while some find PMP ethically permissible, they suggest that oocytes be considered as a scarce resource distributed based on clinical need, and the imposition of a possible age limit.

\section{Medical considerations of AMA}

With respect to oocyte donation, there is a shared consensus that the uterine environment of a post-menopausal woman is similar to that of her younger counterparts. In 1993, Sauer et al, ${ }^{19}$ examined the outcomes of oocyte donation pregnancy in women over the age of 50 using donated oocytes from younger women. They concluded that the age-related decline in female fertility may be reversed by using younger eggs and that the success rate of these pregnancies is equal to their younger comparators. Sauer et $\mathrm{al}^{19}$ contests that the presence of a uterine-specific factor of infertility in AMA is contentious given the good outcomes associated with implanted, donated oocytes. The receptivity and fertile environment 
of the uterus remains adequate in the older population and can be maintained in a state ready for embryo implantation when ovaries are not able to provide normal gametes for reproduction. ${ }^{15,16}$ Thus, older women who are screened both medically and psychologically may have a successful pregnancy when utilizing donated oocytes. This conclusion is echoed in Ameratunga et al's paper. ${ }^{20}$ His team compared women with premature ovarian failure (average age of 28.3) to PMW (average age 45.6). Both groups underwent oocyte donation pregnancy and the investigators found that the PMW had higher risk of gestational hypertension, diabetes, and premature rupture of membranes. ${ }^{20}$

Paulson et $\mathrm{al}^{2}$ studied 77 PMW with no chronic medical conditions who underwent oocyte donation procedures and looked at maternal and fetal outcomes. They concluded that women over the age of 50 were at increased risk for preeclampsia, gestational diabetes, and a majority will deliver by cesarean section. The rates of spontaneous abortion and multiple gestation rate, however, is the same as for their younger counterparts. ${ }^{11}$ These studies, as well as others, conclude that AMA women should be diligently investigated and counseled on antenatal and intrapartum conditions that they are at increased risk of experiencing.

Contrary to the previously mentioned conclusions, Krieg et $\mathrm{al}^{21}$ performed a retrospective cohort analysis of oocyte recipients comparing women over 38 years old to all other women in multiple centers undergoing IVF. His team concludes that AMA women undergoing IVF with donor oocytes are not at increased risk for immediate neonatal complications nor maternal complications. ${ }^{21}$ Antinori et $\mathrm{al}^{22}$ investigated the prenatal and obstetrical outcomes of PMW within a single donor oocyte program. This was a high-powered study including 1,150 patients who were stratified by age brackets of 45-50 and 50-60. ${ }^{20-22}$ Pregnancy rate did not differ between the groups, nor did number of premature births or cases of gestational hypertension. However, a slightly higher number of abortions did occur in the older group. ${ }^{22}$ It is important to note that even the "young" group in this comparison are still considered AMA women, which makes drawing conclusions difficult.

To add to the previously mentioned conclusions, some studies argue that there are significant risks associated with AMA having spontaneous, non-donor oocyte pregnancies. Schimmel et $\mathrm{al}^{3}$ and Tower $^{4}$ state that older women are at greater risk of hypertension, gestational diabetes, chromosomal anomalies, and infants large for gestational age (LGA) which increases risks at delivery (eg, more surgical deliveries). Schimmel et al's ${ }^{15}$ large, adequately powered, retrospective analysis looks at maternal and perinatal outcomes of spontaneously conceived pregnancies in AMA women vs women aged 24-27. The study concluded that AMA comes with significant neonatal and maternal risks including diabetes, hypertension, LGA babies, and emergency cesarean section. ${ }^{15}$ Spontaneous pregnancies in AMA women carry with them additional risks of older ova and chromosomal anomalies, as well as medical risks associated with pregnancy occurring in an aging mother with less physiological reserve and resilience.

The articles in this review explore an area of medicine that has the potential to make impressive advances in the coming decades. In pregnancies conceived with donor oocytes, the uterus of a post-menopausal woman has the ability to maintain a healthy pregnancy. Pregnancies in PMW are considered safe in the absence of preexisting medical comorbidities. Prenatal screening may need to be expanded in this population in order to further identify medical challenges before the pregnancy starts. AMA pregnancies where donor oocytes are not utilized are associated with increased risks such as spontaneous abortion and chromosomal anomalies. Prenatal screening, such as genetic counseling, amniocentesis, and serial ultrasounds have been suggested as potential necessities for AMA pregnancies. ${ }^{12}$ As delayed childbearing is becoming increasingly common, physicians coordinating medical care for these women in the perinatal period should be attentive of the unique risks that advanced age may incur on both mother and child.

\section{Conclusion/discussion}

The literature portrays an overall positive attitude toward pregnancy in AMA. When looking from the ethical and socio-dynamic perspective, of the 12 articles reviewed, the majority (ten) suggest that IVF with egg donation be allowed for PMW. With respect to the medical complications associated with AMA and risk of poor maternal and fetal outcomes, the consensus is that there is a greater risk of complication for spontaneous pregnancy when the mother is of AMA. However, this risk can be mitigated by careful medical screening of the mother and ensuring optimal health status prior to conception. The use of ARTs, such as oocyte donation, is a valuable therapy for women of AMA and in these cases, the woman can carry a pregnancy with a similar risk profile to that of her younger counterparts. It is important to note that complications do not always translate into poor outcomes; eg, higher rates of cesarean sections in PMW have not translated to increased mortality; ${ }^{4}$ likely due to advances in medical therapy, surgical skill, and advanced monitoring. 
In addition, some maternal complications are transient and effectively treated; eg, though gestational hypertension is of concern in pregnancy, once the post-partum period is over, the chance of adverse events occurring returns to the risk of the pre-gravid state. Hypertension during pregnancy may be a warning of future blood pressure concerns, but usually returns to the baseline pre-gravid state in the post-partum period. That being said, subsequent pregnancies will incur the potential for re-entering a disease state. The risks may be exaggerated in the literature, as retrospective studies that show increased morbidity for older pregnant women do not take into account the health of these women before pregnancy. Most fertility centers exclude women with a history of cardiovascular, hypertensive, renal or metabolic disorders as well as women who smoke. Those in good health would have lower pregnancy-related morbidities, independent of age.

Oocyte donation has altered the capability of menopausal women to achieve pregnancy. The majority of articles comparing PMW to their younger comparators conclude that pregnancy success rates do not differ. An important point is that few of the studies document maternal pre-gravid body mass index for the recipient or the donor and also do not report well on clinical or lifestyle factors of the donors other than their mean age. For instance, are physically active women at lesser risk given the known health benefits of this behavior? Does maternal nutrition play a role? Independent of lifestyle factors does the amount and/or distribution of gestational weight gain (GWG) impact donor or recipient outcomes? In the recipient, these factors would significantly impact the pregnancy and, in the donor, may impact egg quality. Thus, without quantitative investigations evaluating these factors one cannot assume that these factors do not impact donor and/or recipient. As such, GWG, maternal diet quality of the donor and recipient, physical activity during pregnancy, and comorbidities are important to mention and should be included in future studies on this topic.

\section{Future directions}

As this is a rapidly progressing field, there are a number of areas of research that can be associated with future studies on AMA, IVF, and oocyte donation. The debate on the ethics of PMP is in its infancy. As with most new health care technologies, the unique needs and interests of different people and cultures will fuel controversy for years to come.

Among the articles which support IVF, most went on to specify future recommendations extending an age limit of 55-60, careful examination of medical and ethical considerations before permission is granted, prioritizing a finite resource (donated oocytes) for a procedure which is costly and has a low success rate, and further assessment of the ethics of egg donation in all age groups. Furthermore, transparent guidelines must consider social and medical factors such as culture, religion, life expectancy, quality of medical care and antenatal management that should be implemented. Further, PMW should be denied IVF if they are deemed physiologically or psychologically unable to cope with a pregnancy.

Additionally, recommendations in the articles against IVF with egg donation for PMW included that physicians should medically evaluate women and their partners, and counsel on the medical and genetic risks associated with conception at an advanced age. Physicians and prospective parents have a moral responsibility to ensure that reproductive choices are protective of both the well-being and welfare of resulting children.

Furthermore, future research on this topic should account and control for or at least attempt to address maternal nutrition, diet quality, physical activity, supplementation use, and implement extended bloodwork panels for older mothers. To ensure high quality intrauterine environments and egg quality this should be done for both donors and egg recipients when studying AMA and ARTs in a prospective fashion which appropriately matches study groups. Finally, the associated cost-benefit analyses could be done by other health care specialists to ensure the most efficient use of limited health care funding.

As technologies advance and their usefulness and safety profiles become more substantial, an interesting discussion would be whether these therapies should be covered under universal health care or insurance. Another moral question that crops up is the idea of once we have acquired new scientific knowledge and developed technology to apply it, do we have a moral obligation to use it? This and many other questions will continue to arise. It is our hope that respect for patient autonomy, desire for patient well-being, and cultural sensitivity will be the foundation of all legislation and guidelines to come. Future research should focus on these societal factors as well as pregnancy rates and clinical outcomes.

\section{Acknowledgment}

Thank you to Erin Liu for assisting with the initial search strategy for the articles.

\section{Disclosure}

The authors report no conflicts of interest in this work. 


\section{References}

1. Benshushan A, Schenker JG. Age limitation in human reproduction: is it justified? J Assist Reprod Genet. 1993;10(5):321-331.

2. Paulson RJ, Boostanfar R, Saadat P, et al. Pregnancy in the sixth decade of life: obstetric outcomes in women of advanced reproductive age. JAMA. 2002;288(18):2320-2323.

3. Schimmel MS, Bromiker R, Hammerman C, et al. The effects of maternal age and parity on maternal and neonatal outcome. Arch Gynecol Obstet. 2015;291(4):793-798.

4. Tower C. Pregnancy in peri- and postmenopausal women: challenges in management. Menopause Int. 2009;15(4):165-168.

5. Smajdor A. The ethics of egg donation in the over fifties. Menopause Int. 2008;14(4):173-177.

6. Parks JA. A closer look at reproductive technology and postmenopausal motherhood. CMAJ. 1996;154(8):1189-1191.

7. Landau R. The promise of post-menopausal pregnancy (PMP). Social Work in Health Care. 2005;40(1):53-69.

8. Eisenberg VH, Schenker JG. Pregnancy in the older woman: scientific and ethical aspects. Int J Gynecol Obstet. 1997;56(2):163-169.

9. Cutas D. Postmenopausal motherhood: immoral, illegal? A case study. Bioethics. 2007;21(8):458-463.

10. Shufaro Y, Schenker JG. Pregnancies beyond the human biological fecundity. Womens Health (Lond). 2012;8(1):49-55.

11. Ekberg ME. Assisted reproduction for postmenopausal women. Hum Fertil (Camb). 2014;17(3):223-230.

12. De Wert G. The Post-Menopause: Playground for Reproductive Technology? Some Ethical Reflections. In: Harris J, Holm S, editors. The Future of Human Reproduction: Ethics, Choice, and Regulation. Oxford: Clarendon Press; 1998:221-237.

13. Kluge EH. Reproductive technology and postmenopausal motherhood. CMAJ. 1994;151(3):353, 355.

14. Edwards RG. Pregnancies are acceptable in post-menopausal women. Hum Reprod. 1993;8(10):1542-1544.

15. Braverman AM. Old, older and too old: age limits for medically assisted fatherhood? Fertil Steril. 2017;107(2):329-333.

16. Berg L, Rostila M, Hjern A. Parental death during childhood and depression in young adults - a national cohort study. J Child Psychol Psychiatry. 2016;57(9):1092-1098.

17. Paulson RJ, Sauer MV. Pregnancies in post-menopausal women: Oocyte donation to women of advanced reproductive age: 'How old is too old?'. Hum Reprod. 1994;9(4):571-572.

18. Smith KR, Mineau GP, Bean LL. Fertility and post-reproductive longevity. Soc Biol. 2002;49(3-4):185-205.
19. Sauer MV, Paulson RJ, Lobo RA. Pregnancy after age 50: application of oocyte donation to women after natural menopause. Lancet. 1993; 341(8841):321-323.

20. Ameratunga D, Weston G, Osianlis T, Catt J, Vollenhoven B. In vitro fertilisation (IVF) with donor eggs in post-menopausal women: are there differences in pregnancy outcomes in women with premature ovarian failure (POF) compared with women with physiological age-related menopause? J Assist Reprod Genet. 2009;26(9-10):511-514.

21. Krieg SA, Henne MB, Westphal LM. Obstetric outcomes in donor oocyte pregnancies compared with advanced maternal age in in vitro fertilization pregnancies. Fertil Steril. 2008;90(1):65-70.

22. Antinori S, Versaci C, Panci C, Caffa B, Gholami GH. Fetal and maternal morbidity and mortality in menopausal women aged $45-63$ years. Hum Reprod. 1995;10(2):464-469.

23. Mori T. Egg donation should be limited to women below 60 years of age. J Assist Reprod Genet. 1995;12(4):229-230.

24. Ethics Committee of the American Society for Reproductive Medicine. Oocyte donation to postmenopausal women. Fertil Steril. 2004;82 Suppl 1:S254-S255.

25. Sauer MV, Paulson RJ, Lobo RA. Reversing the natural decline in human fertility. An extended clinical trial of oocyte donation to women of advanced reproductive age. JAMA. 1992;268(10):1275-1279.

26. Antinori S, Versaci C, Gholami GH, Panci C, Caffa B. Oocyte donation in menopausal women. Hum Reprod. 1993;8(9):1487-1490.

27. Sauer MV, Paulson RJ, Lobo RA. Triplet pregnancy in a 51-year-old woman after oocyte donation. Am J Obstet Gynecol. 1995;172(3): 1044-1045

28. Antinori S, Gholami GH, Versaci C, et al. Obstetric and prenatal outcome in menopausal women: a 12-year clinical study. Reprod Biomed Online. 2002;6(2):257-261.

29. Fonttis AA, Napolitano R, Borda C. Successful pregnancy and delivery after delaying the initiation of progesterone supplementation in a postmenopausal donor oocyte recipient. Reprod Biomed Online. 2004;9(6):611-613.

30. Usta IM, Nassar AH. Advanced maternal age. Part I: obstetric complications. Am J Perinatol. 2008;25(8):521-534

31. Karadag B, Roffi M. Postpartal dissection of all coronary arteries in an in vitro-fertilized postmenopausal woman. Tex Heart Inst J. 2009; 36(2):168-170.

32. Hirst J, Ferrier A. Post-menopausal bleeding: hydatidiform mole a rare cause. Aust N Z J Obstet Gynaecol. 2004;44(5):462-463.
International Journal of Women's Health

\section{Publish your work in this journal}

The International Journal of Women's Health is an international, peerreviewed open-access journal publishing original research, reports, editorials, reviews and commentaries on all aspects of women's healthcare including gynecology, obstetrics, and breast cancer. The manuscript management system is completely online and includes

\section{Dovepress}

a very quick and fair peer-review system, which is all easy to use Visit http://www.dovepress.com/testimonials.php to read real quotes from published authors. 